respondents took an Implicit Association Test, a validated tool measuring attitudes and beliefs that people are not conscious of. They also completed the Hudelson scale assessing the relative responsibility to adapt to migrants. These quantitative results were then discussed as a group with the respondents.

Results The results suggested that more than $80 \%$ (95\% CI: 0.71-0.85) of GPs in training have implicit preferences for their ingroup to the detriment of the exogroup of migrants. Also, 60\% (95\% IC: $0.52-0.67)$ of respondents placed the responsibility to adapt on migrant patients when their values and habits differ from those of the host country.Qualitative data indicate trainees were not aware of these biases.

Conclusion This study shows that GPs trainees have implicit and explicit bias detrimental to ethnic minority groups, of which they are not aware of.

\section{P86 A COMPARATIVE CASE STUDY OF HEALTH-JUSTICE PARTNERSHIPS IN ENGLAND: SERVICE MODELS AND IMPLEMENTATION SUCCESS}

${ }^{1}$ Sarah Beardon*, ${ }^{2}$ Charlotte Woodhead, ${ }^{1}$ Silvie Cooper, ${ }^{3}$ Hazel Genn, ${ }^{1}$ Rosalind Raine. 'Department for Applied Health Research, University College London, London, UK; ${ }^{2}$ Department of Psychological Medicine, King's College London, London, UK; ${ }^{3}$ Faculty of Laws, University College London, London, UK

\subsection{6/jech-2021-SSMabstracts. 172}

Background Social welfare legal problems are root causes of health inequality. Legal advice services can improve socio-economic circumstances and mitigate the financial and social costs of illness. With these aims, partnerships between healthcare and legal services exist across England to support patients with welfare needs. They occur in diverse health settings and take many forms. Success is markedly variable in developing collaborative working and sustaining cross-sector partnerships. This study investigates how such partnerships are implemented and what factors determine differences in implementation outcomes.

Methods A comparative case study of health-justice partnerships across England was undertaken. Services were recruited from different regions, representing diverse health settings and service models. Data were collected through: i) One-to-one semi-structured interviews with staff members and funding organisations; ii) Service records and documentation. In-depth qualitative analysis using the process tracing method was applied to each case study individually. Cross-case comparison of the resulting themes identified key patterns and determinants of implementation success.

Results Nine services participated in the study. Four were based in primary care, four in acute or specialist care (cancer services, mental health services, a children's hospital and an HIV clinic) and one spanned both primary and secondary care. Thirty-eight interviews were undertaken with staff members in frontline and management roles. The case studies provide detailed descriptions of service models, including: colocation or remote working arrangements, referral methods and routes, cross-sector communication and data sharing, funding and management arrangements. The partnerships had experienced different trajectories: while some were long-lived (up to two decades), others had been discontinued, cut in size or had failed to properly establish. Factors influencing sustainability included decision-making processes around funding, strategic-level support and leadership characteristics. The extent of collaborative working was highly variable and influenced by: i) willingness to engage; ii) confidence to engage; iii) ability to engage. These factors were amenable to change. All the partnerships indicated benefits for patient access to legal assistance, positive welfare outcomes, improvements in mental wellbeing and patient experience. Benefits were strengthened where health and legal teams collaborated closely, with improved identification of need, professional skills and service efficiency.

Discussion Health-justice partnerships have a critical role to play in supporting the NHS Covid-19 recovery and tackling health inequalities. Opportunities for cross-sector working are growing with the movements towards Integrated Care Systems and social prescribing. This study provides information to support the successful implementation of heath-justice partnerships in the near and longer term future.

\section{P87 TRENDS IN INEQUALITIES IN LOCAL AUTHORITY SPENDING ON CULTURAL, ENVIRONMENTAL AND PLANNING SERVICES: A LONGITUDINAL STUDY IN ENGLAND, SCOTLAND, AND WALES}

${ }^{1}$ Katie Fahy*, ${ }^{1}$ Alexandros Alexiou, ${ }^{1}$ Kate Mason, ${ }^{1}$ Davara Bennett, ${ }^{2}$ Matt Egan, ${ }^{1}$ David Taylor-Robinson, 'Ben Barr. 'Public Health, Policy and Systems, University of Liverpool, Liverpool, UK; ${ }^{2}$ Public Health, Environments and Society, London School of Hygiene and Tropical Medicine, London, UK

\subsection{6/jech-2021-SSMabstracts.173}

Background Local authorities (LAs) provide Cultural, Environmental, and Planning (CEP) services, such as parks, libraries, and waste collection, that are vital in supporting the health of the communities they serve. There have been significant changes to LA funding recently, most notably due to the UK government's austerity programme. These changes have not affected all places equally. To understand potential impacts on health inequalities, we investigated the extent to which areas have been differentially affected by declines in CEP services spending based on local characteristics.

Methods We conducted a longitudinal ecological study using routinely available data on LA expenditure, as collated in the Place-Based Longitudinal Data Resource. We used generalised estimating equations to determine how expenditure trends varied across 378 LAs in Great Britain between 2009 and 2018 on the basis of country, deprivation, rurality, and local government structure. We investigated the gross expenditure per capita on CEP services, and the CEP expenditure as a proportion of total LA budgets. We conducted analysis using $\mathrm{R}$ v4.0.2.

Results Expenditure per capita for CEP services reduced by 36\% between 2009 and 2018. In England, the reduction in per capita spending was steepest in the most deprived quintile of areas, falling by $5.9 \%$ [95\% CI: 4.7; 7.0] per year, compared to $3.3 \%$ [95\% CI: $2.5 ; 4.1]$ in the least deprived quintile. Budget cuts in Scotland and Wales have been more equitable, showing little differentiation between most and least deprived areas. Welsh LAs have reduced the proportion of total LA budget spent on CEP services more than any other country $(-2.9 \%$ per year [95\% CI: $-4.0 ;-1.8])$, followed by Scotland $(-1.5 \%$ [95\% CI: $-2.8 ;-0.3])$ then England $(-0.5 \%$ [95\% CI: -1.0; 0.1). In England, rural LAs have reduced their CEP spending share more than those in urban areas, and unitary authorities have reduced their share more than those in a two-tier structure. 